\title{
Heat hypersensitivity of ryanodine receptor type 1 mutants implicated in malignant hyperthermia
}

Kotaro Oyama ${ }^{1,2,3,4,{ }^{*}}$, Vadim Zeeb ${ }^{5,}{ }^{*}$, Toshiko Yamazawa ${ }^{6,7}$, Takashi Murayama ${ }^{8}$, Hideto Oyamada ${ }^{9}$, Yoshie Harada ${ }^{10}$, Norio Fukuda ${ }^{3}$, Shin'ichi Ishiwata ${ }^{4}$, Madoka Suzuki ${ }^{2,10,{ }^{*}}$

K.O., V.Z., and T.Y. contributed equally to this work.

${ }^{1}$ Quantum Beam Science Research Directorate, National Institutes for Quantum and Radiological Science and Technology, 1233 Watanukimachi, Takasaki-shi, Gunma 3701292, Japan

2PRESTO, Japan Science and Technology Agency, 4-1-8 Honcho, Kawaguchi-shi, Saitama 332-0012, Japan

${ }^{3}$ Department of Cell Physiology, The Jikei University School of Medicine, 3-25-8 NishiShimbashi, Minato-ku, Tokyo 105-8461, Japan

${ }^{4}$ Department of Physics, Faculty of Science and Engineering, Waseda University, 3-4-1 Okubo, Shinjuku-ku, Tokyo 169-8555, Japan

${ }^{5}$ Institute of Theoretical and Experimental Biophysics, Russian Academy of Sciences, Pushchino, Moscow Region 142292, Russia

${ }^{6}$ Department of Molecular Physiology, The Jikei University School of Medicine, 3-25-8 Nishi-Shimbashi, Minato-ku, Tokyo 105-8461, Japan

${ }^{7}$ Department of Pharmacology, Graduate School of Medicine, The University of Tokyo, 73-1 Bunkyo-ku, Tokyo 113-0033, Japan

${ }^{8}$ Department of Cellular and Molecular Pharmacology, Juntendo University Graduate School of Medicine, 2-1-1 Hongo, Bunkyo-ku, Tokyo 113-8421, Japan

${ }^{9}$ Pharmacological Research Center, Showa University, 1-5-8 Hatanodai, Shinagawa-ku, Tokyo 142-8555, Japan

${ }^{10}$ Institute for Protein Research, Osaka University, 3-2 Yamadaoka, Suita, Osaka 565-0871, Japan 


\section{${ }^{*}$ Corresponding Authors}

\section{Kotaro Oyama}

Quantum Beam Science Research Directorate, National Institutes for Quantum and Radiological Science and Technology

1233 Watanukimachi, Takasaki-shi, Gunma 370-1292, Japan

Tel: +81-27-346-9354, Fax: +81-27-346-9443

E-mail: oyama.kotaro@qst.go.jp

Vadim Zeeb

Institute of Theoretical and Experimental Biophysics,

Russian Academy of Sciences, Pushchino, Moscow Region 142292, Russia

Phone: +7-925-927-63-58, Fax: +7 (4967) 33-05-53

E-mail: zeebvad@gmail.com

Madoka Suzuki

Institute for Protein Research, Osaka University

3-2 Yamadaoka, Suita, Osaka 565-0871, Japan

Tel: +81-6-6879-8628, Fax: +81-6-6879-8590

E-mail: suzu_mado@protein.osaka-u.ac.jp 


\begin{abstract}
Cellular heat-sensing is a universal strategy for avoiding thermal damage and adapting to environments by regulating thermogenic activities. If heat-sensing results in the acceleration of processes governing cellular thermogenesis, hyperthermia can occur. However, how this positive feedback loop contributes to hyperthermia development, especially the gap between heat-sensing and thermogenesis, remains largely unknown. Here, we show that an optically controlled local heat pulse induces an intracellular $\mathrm{Ca}^{2+}$ burst in cultured HEK 293 cells overexpressing ryanodine-receptor-type-1 (RyR1) mutants related to the life-threatening illness malignant hyperthermia $(\mathrm{MH})$, and that the $\mathrm{Ca}^{2+}$ burst originates from heat-induced $\mathrm{Ca}^{2+}$-release (HICR) because of the mutant channels' heat hypersensitivity. Furthermore, the heat hypersensitivity of the four RyR1 mutants was ranked, highlighting the complexity of $\mathrm{MH}$. Our findings reveal the novel cellular heat-sensing mechanism, HICR, is essential for the functional positive feed back loop causing $\mathrm{MH}$, suggesting a well-tuned HICR is fundamental for heat-mediated intracellular signaling.
\end{abstract}




\section{Introduction}

Heat-sensing is essential for avoiding thermal tissue damage and regulating body temperature ${ }^{1}$. Molecular temperature sensors in mammals and insects are temperatureactivated transient receptor potential (TRP) channels ${ }^{2}$. In plants, a reversible temperature-dependent liquid-liquid phase transition of intrinsically disordered proteins has recently been revealed as a thermosensing mechanism ${ }^{3}$. In addition to the absolute temperature, cells also sense how it changes over time. This sensing frequently appears as shifts in chemical and physical processes ${ }^{4}$ or as systems composed of cooperative or antagonistic protein activities. For instance, rapid heating excites cells due to heat-induced displacement of ions near the membranes ${ }^{5,6}$. Rapid cooling increases intracellular $\mathrm{Ca}^{2+}$ concentration $\left(\left[\mathrm{Ca}^{2+}\right]_{\mathrm{i}}\right)$ in muscles and induces muscle contraction, a phenomenon known as rapid cooling contracture ${ }^{7,8}$. In cardiac muscles, heat increases both $\mathrm{Ca}^{2+}$-sensitivity and myofibril tension generation but decreases the amplitude of $\mathrm{Ca}^{2+}$ transients that result in hyperthermic negative inotropy ${ }^{8,9}$. Because of the many different types of heat-sensing mechanisms, one may expect a life-threatening illness when heat-sensing positively affects the processes governing cellular thermogenesis; the thermally accelerated heat release eventually elevates body temperature beyond normal, causing hyperthermia. However, no key molecule, process, or system has been identified as a heat sensor in diseases such as malignant hyperthermia ( $\mathrm{MH}$ ).

$\mathrm{MH}$ is known to be triggered by inhalation of anesthetic gases, depolarizing muscle relaxants, and rarely, exposure to high ambient temperature or vigorous exercise ${ }^{10,11}$. Typical symptoms of $\mathrm{MH}$ are body temperatures elevated above $39^{\circ} \mathrm{C}$ and increased muscle rigidity. These symptoms are fatal if not treated immediately.

$\mathrm{MH}$ is caused by mutations in ryanodine receptor type 1 (RyR1) $\mathrm{Ca}^{2+}$-release channels, dihydropyridine receptors, and Src-homologous-3 and cysteine-rich domaincontaining protein 3 in skeletal muscles ${ }^{10,12,13}$. The majority of human $\mathrm{MH}$-associated mutations have been identified in the RyR1 gene. Normal RyR1 releases $\mathrm{Ca}^{2+}$ from the sarcoplasmic reticulum (SR) during excitation-contraction coupling. In skeletal muscles expressing these mutants, enhanced $\mathrm{Ca}^{2+}$ release from the lumen of the SR elevates $\left[\mathrm{Ca}^{2+}\right]_{\mathrm{i}}$, and uncontrolled hypermetabolism and hyperthermia are induced ${ }^{11}$. Environmental heat stress also triggers $\mathrm{MH}$ in knock-in mice expressing RyR1 
mutations ${ }^{14-16}$. Therefore, the sudden elevation of the body temperature strongly suggests mutual amplification between $\mathrm{Ca}^{2+}$ release and thermogenesis, i.e., a positive feedback loop, in the mechanism of $\mathrm{MH}$ development. However, the intrinsic feature of this positive feedback loop remains elusive because it is unclear how elevated body temperature affects $\mathrm{Ca}^{2+}$ release. In fact, experimental ${ }^{17-20}$ and computational ${ }^{21}$ analyses have demonstrated that elevated temperatures reduce $\mathrm{Ca}^{2+}$ release in wild type (WT) RyR1-3. These results contradict the situation in $\mathrm{MH}$, in which $\mathrm{Ca}^{2+}$ release through mutant RyR1s is maintained even with an elevated body temperature. Furthermore, little is known about how $\mathrm{MH}$ onset occurs when the body temperature is still within the normal range and symptoms begin to appear.

Here, the $\mathrm{Ca}^{2+}$ release induced by heat is shown experimentally to be the key feature of the positive feedback loop between $\mathrm{Ca}^{2+}$ and thermogenesis. By applying optically controlled local heat pulses with a focused near-infrared (IR) laser beam ${ }^{22-26}$ to cultured human embryonic kidney (HEK) 293 cells overexpressing MH mutant RyR1s, we directly examined the heat sensitivities of the mutants. $\mathrm{Ca}^{2+}$ release through RyR1 is dependent on $\left[\mathrm{Ca}^{2+}\right]_{\mathrm{i}}{ }^{27}$. Therefore, with this single cell-based assay system using HEK 293 cells, one can examine the $\mathrm{Ca}^{2+}$ release through RyR1 mutants in situ, without myopathy development ${ }^{28-41}$. The expression levels of endogenous RyRs in HEK 293 cells is negligible compared to those of the expressed RyR1s 37,42 . Transient heating of the cells within the field of view can be carried out nearly simultaneously. Therefore, the following artefacts can be avoided: changes in cell morphology; drifting focus due to thermal expansion of components in the experimental set-up; photo-bleaching of fluorophores; relocation of $\mathrm{Ca}^{2+}$ indicators due to leakage from, or internalization by intracellular compartments; and thermal damage to biomolecules and cells caused by long periods of heat exposure. Moreover, the temperature changes can be controlled with sub-degree accuracy. We successfully compared the heat sensitivity of MH mutants quantitatively; the mutants displayed greater heat sensitivity than WT RyR1. Our results suggest that during $\mathrm{MH}$ onset, a small amount of heat stress can cause elevated $\mathrm{Ca}^{2+}$ release via the heat hypersensitive $\mathrm{MH}$ mutants, causing hypermetabolism and hyperthermia that accelerates $\mathrm{Ca}^{2+}$ release. Thus, the thermogenic cascade becomes unstoppable. 


\section{Results}

\section{Malignant hyperthermia mutants cause heat-pulse-induced $\mathrm{Ca}^{2+}$ release}

HEK 293 cells expressing either WT or mutant RyR1s (Q156K, R164C, and Y523S) were selected across the rank order of the activity of RyR1 mutants with $\mathrm{N}$-terminal region mutations-Q156K was amongst the lowest ranked, Y523S was among the highest ranked, and $\mathrm{R} 164 \mathrm{C}$ had an intermediate ranking ( $\mathrm{WT}<\mathrm{Q} 156 \mathrm{~K}<\mathrm{R} 164 \mathrm{C}<\mathrm{Y} 523 \mathrm{~S}$ ) ${ }^{35,37,40}$ - to test their capabilities as heat sensors (Fig. 1a). The rank order was introduced to compare the amount of $\mathrm{Ca}^{2+}$ leakage among RyR1 mutants ${ }^{37}$. A higher rank indicates higher $\left[\mathrm{Ca}^{2+}\right]_{i}$ and thus lower $\left[\mathrm{Ca}^{2+}\right]$ in the $\mathrm{SR}$ and endoplasmic reticulum $(\mathrm{ER})^{29,30,35,37}$.

Heat stimulation was applied using a $1455-n m$ IR laser $22-26,43$ while fluorescent $\mathrm{Ca}^{2+}$ imaging was performed (Fig. 1b). The temperature in the field of view was elevated almost immediately ( $<100 \mathrm{~ms}$ ) after initiating heat stimulation, and it returned to its original level (re-cooling) when the stimulation was stopped after 2 seconds of heating (Fig. 1c). The amplitude $\Delta T$ was adjustable down to $1^{\circ} \mathrm{C}$ or less at the lower end by the laser's power and distance from where it was focused (Fig. 1d, Supplementary Fig. 1); hence heat pulses of various $\Delta T$ s could be applied to cells in the same field of view (138 $\mu \mathrm{m} \times 138 \mu \mathrm{m}$ ) simultaneously.

No $\left[\mathrm{Ca}^{2+}\right]_{i}$ changes were observed in control cells without induced RyR1 expression (-doxycycline (Dox)) or cells expressing WT RyR1 when heat pulses of $\Delta T=10 \pm 2^{\circ} \mathrm{C}$ were applied at the base temperature $T_{0}=24^{\circ} \mathrm{C}$ (Fig. 2a, Supplementary Movie 1). In contrast, there were rapid $(<\sim 500 \mathrm{~ms})$, large $\left[\mathrm{Ca}^{2+}\right]_{i}$ increases (Ca ${ }^{2+}$ bursts) after initiation of the heat pulse that continued after re-cooling in most R164C cells in the field of view (Fig. 2b, Supplementary Movie 2). In Q156K and Y523S cells, $\left[\mathrm{Ca}^{2+}\right]_{i}$ decreased during the heat pulse, but $\mathrm{Ca}^{2+}$ bursts occurred relatively late ( $\left.>\sim 10 \mathrm{~s}\right)$ and soon ( 2 s) after re-cooling, respectively (Fig. 2c, Supplementary Fig. 2a). The decrease in $\left[\mathrm{Ca}^{2+}\right]_{i}$ during heating (apparent in WT cells in Fig. 2a and Supplementary Movie 1) could be attributable to heat-activated $\mathrm{Ca}^{2+}$ uptake by sarco/endoplasmic reticulum $\mathrm{Ca}^{2+}$ ATPase (SERCA) ${ }^{23,44}$. The maximum changes in the $\mathrm{Ca}^{2+}$ bursts, $\Delta F_{\max } / F_{0}$, during the $20 \mathrm{~s}$ after heating initiation were significantly larger in WT, Q156K, R164C, and Y523S cells than in -Dox cells (Fig. 2d). The experiments were repeated at physiological temperature, 
$T_{0}=36^{\circ} \mathrm{C}$, with the same $\Delta T\left(10 \pm 1^{\circ} \mathrm{C}\right)$. The $\mathrm{Ca}^{2+}$ bursts observed in Q156K, R164C, and Y523S cells were similar to those observed at $T_{0}=24^{\circ} \mathrm{C}$, whereas significant $\mathrm{Ca}^{2+}$ bursts were observed in -Dox and WT cells with mean $\Delta F_{\max } / F_{0}$ values comparable to that of Q156K (Supplementary Fig. 2b). To summarize, $\Delta F_{\max } / F_{0}$ and the fraction of cells exhibiting $\mathrm{Ca}^{2+}$ bursts were largely dependent on the RyR1 mutations and also on $T_{0}$.

\section{$\mathrm{Ca}^{2+}$ flows from the endoplasmic reticulum to the cytosol primarily through ryanodine receptor type 1 during heat-induced $\mathrm{Ca}^{2+}$ bursts}

The RyR1 mutation-dependent variation in heat-induced $\mathrm{Ca}^{2+}$ bursts suggests that the major $\mathrm{Ca}^{2+}$ source is the $\mathrm{ER}$, and that $\mathrm{Ca}^{2+}$ flows from the lumen of $\mathrm{ER}$ to the cytosol through RyR1 channels. The major $\mathrm{Ca}^{2+}$ source was examined in WT RyR1, the mutant RyR1 in the middle of the rank order, R164C, and -Dox cells at physiological temperature, i.e., $36^{\circ} \mathrm{C}$ (Fig. 3). The $\mathrm{Ca}^{2+}$ burst was preserved in all WT, R164C and -Dox cells in $\mathrm{Ca}^{2+}$ free medium, whereas the burst was suppressed when $\mathrm{Ca}^{2+}$ was depleted from the ER by $2 \mu \mathrm{M}$ thapsigargin (a SERCA inhibitor). These results support the idea that the $\mathrm{Ca}^{2+}$ source for the heat-induced $\mathrm{Ca}^{2+}$ burst is not the extracellular space but the ER.

The major $\mathrm{Ca}^{2+}$ channels on the ER membrane are RyRs and inositol trisphosphate receptors (IP $\left.{ }_{3} R s\right)$. Ca ${ }^{2+}$ bursts in WT RyR1 and R164C cells were blocked by $100 \mu \mathrm{M}$ ryanodine (inhibitor of RyR) (Fig. 3a-d), suggesting dominant contributions of respective RyR1 channels expressed in these cells. The suppression of $\mathrm{Ca}^{2+}$ bursts by ryanodine was much less effective in -Dox cells than in WT RyR1 and R164C cells (Fig. $3 e, f)$; thus we confirmed that the contribution of the negligible endogenous $R^{4} R^{45}$ was relatively minor. The contribution of endogenous $I P_{3} R$ was also examined, as we have previously reported that $\mathrm{IP}_{3} \mathrm{R}$ plays a dominant role in heat-induced $\mathrm{Ca}^{2+}$ bursts after recooling in $\mathrm{HeLa}^{44}$ and WI-38 ${ }^{23}$ cells. In fact, there was a significant suppression of $\mathrm{Ca}^{2+}$ bursts in -Dox cells by $100 \mu \mathrm{M}$ 2-APB (unspecific inhibitor of $I P_{3} R^{46-48}$, of which the half maximal inhibition concentration $\left(I C_{50}\right)$ to $I P_{3} R$ is $42 \mu M^{49}$ ) (Fig. 3e,f), suggesting a major contribution of $\mathrm{IP}_{3} \mathrm{R}$ to $\mathrm{Ca}^{2+}$ bursts in -Dox cells. Although the peak intensity of fluo-4 $\left(\Delta F_{\text {max }} / F_{0}\right)$ was also reduced by 2 -APB in WT RyR1 cells (Fig. 3b), $\mathrm{Ca}^{2+}$ bursts were apparent (Fig. 3a). Furthermore, no significant suppression of $\mathrm{Ca}^{2+}$ bursts was observed in R164C cells (Fig. 3c,d). Therefore, we concluded that overexpressed RyR1 channels 
dominate in producing the $\mathrm{Ca}^{2+}$ bursts in their respective cells.

\section{Endoplasmic reticulum-targeted fluorescent $\mathrm{Ca}^{2+}$ probes indicate that the endoplasmic reticulum is a major source of released $\mathrm{Ca}^{2+}$}

To further examine the hypothesis that the ER is the source of $\mathrm{Ca}^{2+}$ in the heat-induced $\mathrm{Ca}^{2+}$ burst, we monitored the $\left[\mathrm{Ca}^{2+}\right]$ in the lumen of $E R\left(\left[\mathrm{Ca}^{2+}\right]_{\mathrm{ER}}\right)$ using an ER-targeted fluorescent $\mathrm{Ca}^{2+}$ probe, G-CEPIA1er ${ }^{50}$, stably expressed in WT RyR1, Q156K, R164C, and Y523S cells. In WT RyR1, the fluorescence intensity of G-CEPIA1er decreased during the heat pulse $\left(\Delta T=10 \pm 1^{\circ} \mathrm{C}\right)$ and then recovered immediately after re-cooling (Fig. 4a, Supplementary Fig. 3a, Supplementary Movie 3). The quick recovery after re-cooling suggests that the decrease during the heat pulse was because of thermal quenching of G-CEPIA1er fluorescence. In cells demonstrating relatively low G-CEPIA1er fluorescence intensity, the signal rise during heating was apparent because of IR-laser-beam scattering (e.g., R164C and Y523S in Supplementary Fig. 3a). A second decrease reached a minimum $\sim 5 \mathrm{~s}$ after re-cooling and then recovered gradually. The initial value $F_{0}$ of $\mathrm{G}-$ CEPIA1er and the second decrease were significantly reduced when $\mathrm{Ca}^{2+}$ was depleted from the ER lumen by $2 \mu \mathrm{M}$ thapsigargin (Fig. 4b, Supplementary Fig. 3a and b). Furthermore, the second decrease appeared to coincide with the $\mathrm{Ca}^{2+}$ burst in the cytosol (Supplementary Fig. 2a). Hence, the second decrease of G-CEPIA1er fluorescence is considered to represent the $\left[\mathrm{Ca}^{2+}\right]_{\mathrm{ER}}$ decrease. The decrease in Q156K cells was comparable to that in WT cells, whereas those in R164C and Y523S cells were significantly lower (Fig. 4b). These results demonstrate positive correlations between the amplitudes of $\left[\mathrm{Ca}^{2+}\right]_{\mathrm{ER}}$ decrease $\left(\Delta F_{\mathrm{min}} / F_{0}\right.$ of G-CEPIA1er $)$ and that of the $\mathrm{Ca}^{2+}$ burst $\left(\Delta F_{\max } / F_{0}\right.$ of fluo-4) (Fig. $4 \mathrm{c}$ ), providing strong support for the conclusion that the heatinduced $\mathrm{Ca}^{2+}$ burst arises from $\mathrm{Ca}^{2+}$ release from the ER through RyR1.

\section{Variation in heat sensitivity among wild-type and mutant ryanodine receptor type 1 channels and its ambient temperature sensitivity}

Last, the heat sensitivities of WT and RyR1 mutants were examined systematically by exposing cells to heat pulses of variable $\Delta T$ and evaluating the fraction of cells exhibiting $\mathrm{Ca}^{2+}$ bursts (Fig. 5a, Supplementary Fig. 4). At $\mathrm{T}_{0}=36^{\circ} \mathrm{C}$, the $\mathrm{Ca}^{2+}$ burst was more 
frequently observed when $\Delta T$ was larger in WT and all mutant cells. However, there was a gradient among them. For example, approximately $40 \%$ of $\mathrm{R} 164 \mathrm{C}$ cells showed $\mathrm{Ca}^{2+}$ bursts in response to a heat pulse of $\Delta T=1^{\circ} \mathrm{C}$, but $\mathrm{Ca}^{2+}$ bursts were only observed in $20 \%$ or fewer WT and other mutant cells; i.e., R164C cells showed the highest heat sensitivity, Y523S and Q156K cells were less sensitive, and WT cells were the least sensitive. This variation in heat sensitivity was quantitatively compared using the threshold values of $\Delta T\left(\Delta T_{\text {th }}\right)$ at which $50 \%$ of the cells responded (Fig. $5 \mathbf{b}$ ). This analysis is independent from spontaneous (non-thermal) $\left[\mathrm{Ca}^{2+}\right]_{\mathrm{i}}$ fluctuations and the amplitude of the $\mathrm{Ca}^{2+}$ burst, which can depend on $\left[\mathrm{Ca}^{2+}\right]_{\mathrm{ER}}$. Based on this data, one can draw a rank order in $\Delta T_{\text {th }}$ as $\mathrm{R} 164 \mathrm{C}<<\mathrm{Y} 523 \mathrm{~S}<\mathrm{Q} 156 \mathrm{~K}<\mathrm{WT}$ at both $T_{0}=24^{\circ} \mathrm{C}$ and $36^{\circ} \mathrm{C}$ (Fig. $5 \mathrm{~b}$ and c, Supplementary Figs

5 and $6 a, b)$. We further examined R164L, which has a rank-order of activity similar to that of $\mathrm{R} 164 \mathrm{C}^{37,40}$, and found that the $\Delta T_{\text {th }}$ of $\mathrm{R} 164 \mathrm{~L}$ was comparable to that of $\mathrm{R} 164 \mathrm{C}$. It was also apparent that Q156K and WT cells were more heat-sensitive at $T_{0}=36^{\circ} \mathrm{C}$ than at $T_{0}=24^{\circ} \mathrm{C}$.

\section{Discussion}

$\mathrm{MH}$ is a life-threatening illness caused by mutations in RyR 1 that manifests as a sudden and unstoppable temperature elevation at the whole-body level. Here, we propose a link between the macroscopic whole-body temperature elevation of $\mathrm{MH}$ and the nanoscopic thermodynamics of RyR1 mutants. The current study successfully demonstrated heat-induced release of $\mathrm{Ca}^{2+}$ in selected MH RyR1 mutants using local heating with a focused IR laser beam, and that the mutant RyR1s are more heat-sensitive than WT RyR1s. The heat hypersensitivity and $\mathrm{Ca}^{2+}$ release induced by heat pulses in mutant RyR1 channels suggest that positive feedback between thermogenesis and $\mathrm{Ca}^{2+}$ release is responsible for $\mathrm{MH}$ progression. When $\mathrm{Ca}^{2+}$ leakage through $\mathrm{MH}$ RyR1 mutants is enhanced by $\mathrm{MH}$ inducers (e.g., inhalation of anesthetics), the resulting $\left[\mathrm{Ca}^{2+}\right]_{i}$ increase leads to thermogenesis by SERCA ${ }^{51}$ and possibly also by $\mathrm{Ca}^{2+}$ leakage itself ${ }^{52}$. It is noteworthy that both SERCA and RyR1 are localized in the ER membrane. Then, the temperature elevation results in $\mathrm{Ca}^{2+}$ release through the channels, as demonstrated in the present study (for a schematic, see Fig. $\mathbf{5 d}$ ). We propose naming this process heatinduced $\mathrm{Ca}^{2+}$-release (HICR). A critical role for HICR in the aggravation of $\mathrm{MH}$ is also 
suggested, especially at the initial stage, when low levels of heat stress originating from metabolism or exercise could initiate $\mathrm{Ca}^{2+}$ release because of the heat hypersensitivity of $\mathrm{MH}$ mutants. The HICR could coincide with the positive-feed back loop over a relatively longer time scale that Hamilton et al. suggested ${ }^{53,54}$. They showed that increased $\left[\mathrm{Ca}^{2+}\right]_{\mathrm{i}}$ activates the production of both reactive oxygen (ROS) and nitrogen (RNS) species in heterozygous knock-in mice with a Y524S (Y522S in human) mutation; these products then modify RyR1 and other skeletal muscle proteins to promote $\mathrm{Ca}^{2+}$ releases in an unclarified manner. Because of the relatively short time scale of HICR, the slower processes of ROS/RNS production and post-transcriptional modifications may contribute to the additional complexity of HICR and thus of $\mathrm{MH}$. We found that $\Delta T_{\text {th }}$ is smaller in R164C and Y523S cells than in WT cells. This result is consistent with previous reports that muscle contraction and sudden death can be triggered by a moderate temperature increase in R165C (R163C in human) and Y524S knock-in mice that correspond to rabbit $\mathrm{R} 164 \mathrm{C}$ and Y523S mutants, respectively ${ }^{14,15}$. Durham et al. have also reported that $\left[\mathrm{Ca}^{2+}\right]_{\mathrm{i}}$ was increased in the skeletal muscles of Y524S knock-in mice more than that in WT mice in response to the same degree of temperature elevation ${ }^{53}$. Among the mutants, the rank order did not necessarily reflect the order in $\Delta T_{\text {th. }}$. The Y523S channel mutant is leakier than R164C(L) (Fig. 1a) ${ }^{29,30,37}$. However, the $\Delta T_{\text {th }}$ was greater in $\mathrm{Y} 523 \mathrm{~S}$ cells than in $\mathrm{R} 164 \mathrm{C}(\mathrm{L})$ cells. According to previous studies examining caffeine-induced $\mathrm{Ca}^{2+}$ release ${ }^{29,30,37}$, one possible reason is that depletion of basal $\left[\mathrm{Ca}^{2+}\right]_{\mathrm{ER}}$ before the heat pulse reduces the amount of $\mathrm{Ca}^{2+}$ released from the ER. Because the Y523S mutant is the most destabilized channel, it would release more $\mathrm{Ca}^{2+}$, even without a heat pulse. Thus, the excess temperature elevation probably has a lesser effect on $\mathrm{Ca}^{2+}$ release through the Y523S channel than the R164C and R164L channels.

The heat hypersensitivity of $\mathrm{MH}$ mutants revealed in the present study could be caused by destabilized interactions between N-terminal domains ( $\mathrm{N}, \mathrm{B}$ and $\mathrm{C}$ ) and neighboring domains at the "N-terminal hotspot" of residues 35-614, one of three known hotspots related to $\mathrm{MH}^{55,56}$ (Supplementary Fig. 7). The Q156 and R164 in domain $A$ interact with domain $B$ to form interface 1 within the $A B C$ subunit at the $N$ terminus $^{57}$. At the bottom of domain A (interface 4), R164 interacts with the core domain ${ }^{57}$. Y523 is exposed at the surface of domain C, facing the cytosolic shell domain 
(interface 3$)^{57}$. One possible explanation for our data is that the inter-domain interactions are destabilized by heat in the mutants and cause $\mathrm{Ca}^{2+}$ leakage followed by intracellular $\mathrm{Ca}^{2+}$ bursts that are more heat-sensitive than in the WT. Hence, the heat hypersensitivity identified in the current study may be a common property of MH RyR1 mutants. This idea is supported by the literature because it has been reported that $\mathrm{MH}$ RyR1 mutant structures are generally unstable under environmental heat stress ${ }^{57-59}$. We have also reported that ER Ca ${ }^{2+}$ levels in $\mathrm{R} 164 \mathrm{C}(\mathrm{L})$ and other $\mathrm{N}$-terminal mutant cells were lower at $36^{\circ} \mathrm{C}$ than at room temperature relative to $\mathrm{WT}^{37}$. Further confirmation of this hypothesis would be a target for future experiments using molecular dynamics simulations, which have been useful for studying the effect of inter-domain interface mutations on the heat sensitivity of RyRs ${ }^{58,60,61}$.

In summary, we applied local heating and found that RyR1 heat-sensing results in HICR. Our results revealed that the heat hypersensitivity of $\mathrm{MH}$ mutants is dependent on the experimental temperature. Thus, a positive feedback loop can be formed between heat-sensing and thermogenesis to cause an abnormally elevated body temperature in $\mathrm{MH}$. This hypothesis can explain the overlap between the $\mathrm{MH}$ mechanism and exertional heat stroke, in which hyperthermia is induced by physical exertion in patients expressing $\mathrm{MH}$ mutants ${ }^{62-64}$. Apart from the essential role of the anomalous positive feedback loop in hyperthermia progression, the current data also suggest that a well-tuned HICR could be fundamental to intracellular signaling.

\section{Materials and Methods}

\section{Chemicals}

Dulbecco's Modified Eagle Medium (DMEM) (08488-55), L-glutamine (16948-04), and hygromycin (09287-84) were purchased from Nacalai Tesque Inc. (Kyoto, Japan). Fetal bovine serum (FBS) (10437-028), penicillin and streptomycin (15140-122), Lipofectamine 2000 (11668) and fluo-4 AM (F14217) were purchased from Thermo Fisher Scientific (Waltham, MA, USA). Blasticidin (ant-bl-1) was purchased from InvivoGen (San Diego, CA, USA). Collagen type 1 (IFP9660) was purchased from the Research Institute for the Functional Peptides (Yamagata, Japan). Doxycycline (Dox) (D9891), 2-aminoethoxydiphenyl borate (2-APB) (D9754) and poly(methyl methacrylate) 
(PMMA, $\mathrm{M}_{\mathrm{w}}$ 15,000) (200336) were purchased from Sigma-Aldrich (St. Louis, MO, USA). Thapsigargin (586005) was purchased from Merck (Darmstadt, Germany). Ryanodine (185-02821) was purchased from FUJIFILM Wako Pure Chemical Corporation (Osaka, Japan). Europium (III) thenoyltrifluoroacetonate trihydrate (Eu-TTA) (21392-96-1) was purchased from Acros Organics (Pittsburgh, PA, USA). The stocks of $1 \mathrm{mM}$ fluo-4 AM in DMSO, $2 \mathrm{mM}$ thapsigargin in DMSO, $10 \mathrm{mM}$ ryanodine in distilled water, and $100 \mathrm{mM} 2-$ APB in DMSO were stored at $-20^{\circ} \mathrm{C}$ until used.

\section{Cell culture}

HEK 293 cells stably transformed with rabbit skeletal muscle RyR1 or its mutants (Q156K, $\mathrm{R} 164 \mathrm{C} / \mathrm{L}$, or Y523S; human Q155K, R163C/L, or Y522S) were generated as reported previously $35,37,65$. The expression of RyR1 is inducible by Dox using the Flp-In T-Rex system (Thermo Fisher Scientific); hence the system is suitable for investigating the functions of fatal RyR1 mutants in living cells. The expression levels of WT and mutant RyR1s were similar.

The HEK 293 cells were cultured in flasks or on dishes coated with collagen (TPP Techno Plastic Products AG, Trasadingen, Switzerland) in culture medium (DMEM containing 10\% FBS, $2 \mathrm{mM}$ L-glutamine, 100 units $\mathrm{ml}^{-1}$ penicillin, and $100 \mu \mathrm{g} \mathrm{ml}^{-1}$ streptomycin) with added $100 \mu \mathrm{g} \mathrm{ml}^{-1}$ hygromycin and $15 \mu \mathrm{g} \mathrm{ml}^{-1}$ blasticidin at $37^{\circ} \mathrm{C}$ in $5 \% \mathrm{CO}_{2}$. To coat the flasks and dishes with collagen, they were filled with a $0.001 \%$ collagen type 1 solution in distilled water for $1 \mathrm{~h}$ at $37^{\circ} \mathrm{C}$. The flasks and dishes were washed with the fresh culture medium just before culturing the cells.

\section{$\mathrm{Ca}^{2+}$ imaging}

Cells were seeded on collagen-coated glass base dishes (AGC Techno Glass, Shizuoka, Japan) at $37^{\circ} \mathrm{C}$ in $5 \% \mathrm{CO}_{2}$ for $1-3$ days. To induce RyR1 expression, the culture medium was replaced with the medium containing $2 \mathrm{\mu g} \mathrm{ml}^{-1}$ Dox. Cells were incubated for 24-36 $\mathrm{h}$ before the experiments were initiated.

Cytoplasmic $\mathrm{Ca}^{2+}$ dynamics were studied using the fluorescent $\mathrm{Ca}^{2+}$ probe fluo$4 \mathrm{AM}$. The cells were incubated in HEPES-buffered saline (HBS) $(140 \mathrm{mM} \mathrm{NaCl}, 5 \mathrm{mM} \mathrm{KCl}$, $1 \mathrm{mM} \mathrm{MgCl}_{2}, 1 \mathrm{mM} \mathrm{Na}_{2} \mathrm{HPO}_{4}, 10 \mathrm{mM}$ HEPES, $2 \mathrm{mM} \mathrm{CaCl}$, 5 mM D-glucose, pH 7.4, adjusted with $\mathrm{NaOH}$ ) containing $1 \mu \mathrm{M}$ fluo-4 AM for 30 min at room temperature. The 
solution was replaced with fresh HBS, and the cells were incubated under the microscope for at least 10 min before observation to allow temperature stabilization to $24 \pm 1^{\circ} \mathrm{C}$ or $36 \pm 0.5^{\circ} \mathrm{C}$. Where indicated, the cells were observed in $\mathrm{Ca}^{2+}$-free solution (140 $\mathrm{mM} \mathrm{NaCl}, 5 \mathrm{mM} \mathrm{KCl}, 1 \mathrm{mM} \mathrm{MgCl}$, $1 \mathrm{mM} \mathrm{Na} \mathrm{HPO}_{4}, 10 \mathrm{mM}$ HEPES, $5 \mathrm{mM}$ D-glucose, 2 mM EGTA, pH 7.4, adjusted with $\mathrm{NaOH}$ ) at least 15 min after incubation. To inhibit the activity of SERCA or $I P_{3} R$, the cells were incubated in HBS containing $1 \mu \mathrm{M}$ fluo-4 AM and either $2 \mu \mathrm{M}$ thapsigargin or $100 \mu \mathrm{M} 2-\mathrm{APB}$ for $30 \mathrm{~min}$ at $24^{\circ} \mathrm{C}$ and then observed in HBS containing $2 \mu \mathrm{M}$ thapsigargin or $100 \mu \mathrm{M}$ 2-APB. To inhibit RyR1, the fluo-4-loaded cells were observed in HBS containing $100 \mu \mathrm{M}$ ryanodine.

To monitor $\mathrm{Ca}^{2+}$ dynamics in the ER, HEK 293 cells stably expressing GCEPIA1er ${ }^{50}$ were prepared as follows. Lentiviral vectors harboring the G-CEPIA1er construct were produced by replacing the cDNA of enhanced green fluorescent protein (GFP) in pCL20c-MSCV-AcGFP-WPRE (kindly provided by Dr. Y. Ohashi, The University of Tokyo, Tokyo, Japan) ${ }^{66}$. HEK 293T cells were co-transfected with four plasmids, pCAGkGP1.1R, pCAG4RTR2, pCAG-VSV-G, and pCL20c-MSCV-G-CEPIA1er-WPRE, using Lipofectamine 2000 . The cells were incubated at $37^{\circ} \mathrm{C}$ in $5 \% \mathrm{CO}_{2}$ for $16 \mathrm{~h}$. Then the culture medium was replaced, and the cells were incubated at $37^{\circ} \mathrm{C}$ in $5 \% \mathrm{CO}_{2}$ for $36 \mathrm{~h}$. The lentivirus-containing medium was collected and cleared by centrifugation at 1,500 rpm for $5 \mathrm{~min}$ at $4^{\circ} \mathrm{C}$. To concentrate the lentivirus, the supernatant was centrifuged at $10,000 \mathrm{rpm}$ at $4^{\circ} \mathrm{C}$ overnight. The pellets were suspended in $50 \mu \mathrm{l}$ phosphate buffered saline and stored at $-80^{\circ} \mathrm{C}$ until used. HEK 293 cells expressing WT RyR1 or the mutant RyR1s were transfected with the virus for G-CEPIA1er. Approximately $80 \%-95 \%$ of the cells were transduced. After at least two additional passages, the cells were used in the experiments.

\section{Optical set-up}

The microscope with local heating apparatus was set up as described in our previous work $^{22-26,43}$. Briefly, the local temperature around the cell was increased by a $1455-\mathrm{nm}$ IR laser beam that is efficiently absorbed by water (KPS-STD-BT-RFL-1455-02-CO; Keopsys, Lannion, France). The duration of irradiation was controlled by a mechanical shutter (SSH-C4B; Sigma Koki, Tokyo, Japan). The laser power was measured using a 
thermal disk sensor (LM-3; Coherent, Santa Clara, CA, USA) and a power meter (FieldMaster; Coherent) at the level of the sample after passage through the objective lens. The permeability of the IR laser beam, which is the ratio of the output laser power at the level of the sample to the input laser power, was approximately $1.6 \%$. Fluo-4, GCEPIA1er, and Eu-TTA were excited by a solid-state illuminator (SPECTRA Light Engine; Lumencor, Beaverton, OR, USA; 377/50 nm for Eu-TTA and 485/20 nm for fluo-4 and GCEPIA1er). The fluorescence and the bright-field images were observed with an inverted microscope (IX70; Olympus, Tokyo, Japan), equipped with a dichroic mirror (DM505; Olympus), an emission filter (BA515IF; Olympus), an objective lens (PlanApo N 60×/1.45 Oil, Olympus), and an electron multiplying charge coupled device (EMCCD) camera (iXon ${ }^{\mathrm{EM}}+897$; Andor Technology, Belfast, UK). The temperature of the solutions on the sample stage was adjusted to $36 \pm 0.5^{\circ} \mathrm{C}$ using a thermostatically controlled incubator (INUCP-KRi-H2-F1; Tokai Hit, Shizuoka, Japan); otherwise the temperature of the solutions was $24 \pm 1^{\circ} \mathrm{C}$.

\section{Analyses}

The microscopic images were analyzed with ImageJ (National Institutes of Health, Bethesda, MD, USA).

The changes in local temperature were measured by thermal quenching of EuTTA that had been spin-coated on a glass base dish by a solution containing $5 \mathrm{mg} \mathrm{ml}^{-1}$ Eu-TTA and $10 \mathrm{mg} \mathrm{ml}^{-1}$ PMMA in acetone ${ }^{23-25}$. Relative changes in the intensity of Eu-TTA were calculated by $\Delta F / F_{0}=\left(F_{\text {heating }}-l_{\text {laser }}\right) /\left(F_{\text {before }} I_{\text {back }}\right)-1$, where $F_{\text {heating }}$ was the intensity at the end of the heating period, i.e., just before the IR laser beam was shut off, and $l_{\text {laser }}$ was the background intensity caused by light scattering of the IR laser beam. Iback was the background intensity when the excitation light was off. Photo-bleaching was corrected by fitting a single exponential curve. $\Delta F / F_{0}$ of Eu-TTA was converted to $\Delta T$ using the relationship between $\Delta T$ and $\Delta F / F_{0}\left(-2.7 \%{ }^{\circ} \mathrm{C}^{-1} \text { at } 24{ }^{\circ} \mathrm{C} \text { and }-4.1 \%{ }^{\circ} \mathrm{C}^{-1} \text { at } 36^{\circ} \mathrm{C}\right)^{23,25}$.

To calculate changes in the fluorescence intensities of fluo-4 and G-CEPIA1er, the outlines of cells were manually tracked in the bright-field images. Then the fluorescence intensities of fluo-4 and G-CEPIA1er were measured within the outlined areas. The distance between the area center and a laser spot was defined as the distance 
between the cell and the heat source. The change in the fluorescence intensity $(\Delta F)$ of fluo-4 was calculated from $F-F_{\text {before, }}$ where $F$ was the fluorescence intensity at an arbitrary time, and $F_{\text {before }}$ was the intensity just before heating was initiated (i.e., $10 \mathrm{~s}$ after beginning the observation). The basal fluorescence intensity of fluo-4 $\left(F_{0}\right)$ was calculated from $F_{\text {before}}-I_{\text {back. }}$. The peak intensity of fluo-4 $\left(\Delta F_{\max } / F_{0}\right)$ was calculated from the maximum $\Delta F / F_{0}$ during the $20 \mathrm{~s}$ after heating initiation. Light scattering by the IR laser beam (Supplementary Movie 1 ) was subtracted to calculate $\Delta F_{\text {max }} / F_{0}$ during heating. No noticeable photo-bleaching of fluo-4 was observed during measurement (Fig. 2a).

The $\Delta F_{\max } / F_{0}$ of spontaneous $\left[\mathrm{Ca}^{2+}\right]_{i}$ fluctuations in Supplementary Fig. 8 was calculated by $\left(F_{\text {max }}-F_{\text {before }}\right) /\left(F_{\text {before }}-I_{\text {back }}\right)$. To equalize the exposure time of excitation light $(485 \mathrm{~nm})$ and that in the heating experiments, $F_{\text {before }}$ was set to the fluorescence intensity $10 \mathrm{~s}$ after starting the observation. $F_{\max }$ was the maximum intensity obtained from 10 to $30 \mathrm{~s}$ after starting the observation. The cumulative probability of $\Delta F_{\max } / F_{0}$ was fitted by a cumulative distribution function of the Gaussian distribution ${ }^{67}$

$$
F(x)=\frac{1}{\sqrt{2 \sigma^{2} \pi}} \int_{-\infty}^{x} \mathrm{e}^{-\frac{(t-\mu)^{2}}{2 \sigma^{2}}} d t
$$

where $\mu$ and $\sigma$ are the mean and the standard deviation (SD) of the Gaussian distribution, respectively. The fitting by least squares methods was performed in Excel 2016 (Microsoft, Redmond, WA, USA) using the following equation:

$$
F(x)=\frac{1}{2}\left[1+\operatorname{erf}\left(\frac{x-\mu}{\sqrt{2 \sigma^{2}}}\right)\right]
$$

where $\operatorname{erf}(x)$ is an error function. The threshold $\Delta F_{\text {th }}$ of $\Delta F_{\text {max }} / F_{0}$ was defined as $\mu+1.96 \sigma$. If $\Delta F_{\text {max }} / F_{0}$ induced by a heat pulse was higher than $\Delta F_{\text {th, }}$ the $\left[\mathrm{Ca}^{2+}\right]_{\mathrm{i}}$ increase response induced by the heat pulse was considered significant.

The threshold of $\Delta T\left(\Delta T_{\text {th }}\right)$ was defined as the $\Delta T$ that induced significant $\left[\mathrm{Ca}^{2+}\right]_{\mathrm{i}}$ increases $\left(\Delta F_{\text {max }} / F_{0}>\Delta F_{\text {th }}\right)$ in $50 \%$ of cells (Fig. 5b).

The $\Delta F_{\min } / F_{0}$ of G-CEPIA1er was calculated from $\left(F_{\min }-F_{\text {before }}\right) /\left(F_{\text {before }}-l_{\text {back }}\right)$, where $F_{\min }$ was the minimum intensity of G-CEPIAler obtained from $2.4 \mathrm{~s}$ to $10 \mathrm{~s}$ after heating initiation. In this calculation of $\Delta F_{\min } / F_{0}$, photo-bleaching was corrected by fitting with a single exponential curve in Excel 2016 (Microsoft). 


\section{Statistical analysis}

Multiple groups were compared using the Steel test. For comparisons of two independent samples, the Mann-Whitney $U$ test was used. These tests were performed using EZR (ver 1.51) ${ }^{68}$. Statistical significance was described by $p$ values. Linear regression analysis was performed using OriginPro2016 software (OriginLab, Northampton, MA, USA). 


\section{Acknowledgments}

We sincerely thank the late Professor David H. MacLennan (University of Toronto, Toronto, ON, Canada) for valuable suggestions about useful mutagenesis strategies for RyR1 cDNA constructs and constant encouragement. We also thank Ms. Tomomi Arai (Waseda University) for technical assistance. This work was supported by JSPS KAKENHI Grant Numbers 25707035 (to K.O.), $19 K 07306$ (to T.Y.), JP22227005 (to S.I.), and $19 \mathrm{H} 03198$ (to M.S.), by the Russian Advanced Research Foundation, Grant Volkhov-A (to V.Z.), by the Japan Science and Technology Agency JPMJPR17P3 (to K.O.) and JPMJPR15F5 (to M.S.), and by the Human Frontier Science Program RGP0047/2018 (to V.Z. and M.S.).

\section{Author contributions}

K.O., V.Z., T.Y., S.I., and M.S. designed the research study; K.O., V.Z., and T.Y. performed the experiments; T.M., H.O., J.S., K.K., and M.I. contributed new reagents/analytic tools; K.O. analyzed the data; K.O., V.Z., T.Y., Y.H., N.F., S.I., and M.S. contributed to data analysis, and all authors were involved in drafting this work.

\section{Competing interests}

The authors declare no conflicts of interest. 


\section{References}

1. Tan, C. L. \& Knight, Z. A. Regulation of body temperature by the nervous system. Neuron 98, 3148 (2018).

2. Patapoutian, A., Peier, A. M., Story, G. M. \& Viswanath, V. ThermoTRP channels and beyond: mechanisms of temperature sensation. Nat. Rev. Neurosci. 4, 529-539 (2003).

3. Jung, J.-H. et al. A prion-like domain in ELF3 functions as a thermosensor in Arabidopsis. Nature 585, 256-260 (2020).

4. Kondepudi, D. \& Prigogine, I. Modern thermodynamics: from heat engines to dissipative structures. (John Wiley \& Sons, Hoboken, 1998).

5. Shapiro, M. G., Homma, K., Villarreal, S., Richter, C. P. \& Bezanilla, F. Infrared light excites cells by changing their electrical capacitance. Nat. Commun. 3, 736 (2012).

6. Liu, Q., Frerck, M. J., Holman, H. A., Jorgensen, E. M. \& Rabbitt, R. D. Exciting cell membranes with a blustering heat shock. Biophys. J. 106, 1570-1577 (2014).

7. Sakai, T. Rapid cooling contracture. Jpn. J. Physiol. 36, 423-431 (1986).

8. Bers, D. M. Excitation-contraction coupling and cardiac contractile force. (Kluwer Academic Publishers, Dordrecht, 2001).

9. Ishii, S. et al. Thermal activation of thin filaments in striated muscle. Front. Physiol. 11, 278 (2020).

10. Lanner, J. T., Georgiou, D. K., Joshi, A. D. \& Hamilton, S. L. Ryanodine receptors: structure, expression, molecular details, and function in calcium release. Cold Spring Harb. Perspect. Biol. 2, a003996 (2010).

11. Rosenberg, H., Pollock, N., Schiemann, A., Bulger, T. \& Stowell, K. Malignant hyperthermia: a review. Orphanet J. Rare Dis. 10, 93 (2015).

12. Riazi, S., Kraeva, N. \& Hopkins, P. M. Malignant hyperthermia in the post-genomics era: new perspectives on an old concept. Anesthesiology 128, 168-180 (2018).

13. Ibarra Moreno, C. A. et al. An assessment of penetrance and clinical expression of malignant hyperthermia in individuals carrying diagnostic ryanodine receptor 1 gene mutations. Anesthesiology 131, 983-991 (2019).

14. Yang, T. et al. Pharmacologic and functional characterization of malignant hyperthermia in the R163C RyR1 knock-in mouse. Anesthesiology 105, 1164-1175 (2006).

15. Chelu, M. G. et al. Heat- and anesthesia-induced malignant hyperthermia in an RyR1 knock-in mouse. FASEB J. 20, 329-330 (2006).

16. Lopez, J. R., Kaura, V., Diggle, C. P., Hopkins, P. M. \& Allen, P. D. Malignant hyperthermia, environmental heat stress, and intracellular calcium dysregulation in a mouse model expressing the p.G2435R variant of RYR1. Br. J. Anaesth. 121, 953-961 (2018).

17. Sitsapesan, B. Y. R. et al. Sheep cardiac sarcoplasmic reticulum calcium-release channels: 
modification of conductance and gating by temperature. J. Physiol. 434, 469-488 (1991).

18. Ferrier, G. R., Smith, R. H. \& Howlett, S. E. Calcium sparks in mouse ventricular myocytes at physiological temperature. Am. J. Physiol. Heart Circ. Physiol. 285, H1495-H1505 (2003).

19. Protasi, F. et al. All three ryanodine receptor isoforms generate rapid cooling responses in muscle cells. Am J Physiol Cell Physiol 286, C662-C670 (2004).

20. Fu, Y. et al. Temperature dependence and thermodynamic properties of $\mathrm{Ca}^{2+}$ sparks in rat cardiomyocytes. Biophys. J. 89, 2533-2541 (2005).

21. Moskvin, A. S. S., laparov, B. I. I., Ryvkin, A. M. M., Solovyova, O. E. E. \& Markhasin, V. S. Electron-conformational transformations govern the temperature dependence of the cardiac ryanodine receptor gating. JETP Lett. 102, 62-68 (2015).

22. Oyama, K. et al. Microscopic heat pulses induce contraction of cardiomyocytes without calcium transients. Biochem. Biophys. Res. Commun. 417, 607-612 (2012).

23. Itoh, H., Oyama, K., Suzuki, M. \& Ishiwata, S. Microscopic heat pulse-induced calcium dynamics in single WI-38 fibroblasts. BIOPHYSICS 10, 109-119 (2014).

24. Shintani, S. A., Oyama, K., Fukuda, N. \& Ishiwata, S. High-frequency sarcomeric auto-oscillations induced by heating in living neonatal cardiomyocytes of the rat. Biochem. Biophys. Res. Commun. 457, 165-170 (2015).

25. Oyama, K. et al. Triggering of high-speed neurite outgrowth using an optical microheater. Sci. Rep. 5, 16611 (2015).

26. Oyama, K. et al. Directional bleb formation in spherical cells under temperature gradient. Biophys. J. 109, 355-364 (2015).

27. Endo, M. Calcium-induced calcium release in skeletal muscle. Physiol. Rev. 89, 1153-1176 (2009).

28. Tong, J. et al. Caffeine and halothane sensitivity of intracellular $\mathrm{Ca}^{2+}$ release is altered by 15 calcium release channel (ryanodine receptor) mutations associated with malignant hyperthermia and/or central core disease. J. Biol. Chem. 272, 26332-26339 (1997).

29. Tong, J., McCarthy, T. V \& MacLennan, D. H. Measurement of resting cytosolic $\mathrm{Ca}^{2+}$ concentrations and $\mathrm{Ca}^{2+}$ store size in HEK-293 cells transfected with malignant hyperthermia or central core disease mutant $\mathrm{Ca}^{2+}$ release channels. J. Biol. Chem. 274, 693-702 (1999).

30. Avila, G. \& Dirksen, R. T. Functional effects of central core disease mutations in the cytoplasmic region of the skeletal muscle ryanodine receptor. J. Gen. Physiol. 118, 277-290 (2001).

31. Brini, M. et al. $\mathrm{Ca}^{2+}$ signaling in HEK-293 and skeletal muscle cells expressing recombinant ryanodine receptors harboring malignant hyperthermia and central core disease mutations. $J$. Biol. Chem. 280, 15380-15389 (2005).

32. Jiang, D. et al. Reduced threshold for luminal $\mathrm{Ca}^{2+}$ activation of RyR1 underlies a causal mechanism of porcine malignant hyperthermia. J. Biol. Chem. 283, 20813-20820 (2008). 
33. Sato, K., Pollock, N. \& Stowell, K. M. Functional studies of RYR1 mutations in the skeletal muscle ryanodine receptor using human RYR1 complementary DNA. Anesthesiology 112, 1350-1354 (2010).

34. Sato, K., Roesl, C., Pollock, N. \& Stowell, K. M. Skeletal muscle ryanodine receptor mutations associated with malignant hyperthermia showed enhanced intensity and sensitivity to triggering drugs when expressed in human embryonic kidney cells. Anesthesiology 119, 111-118 (2013).

35. Nakano, M. et al. Construction and expression of ryanodine receptor mutants relevant to malignant hyperthermia patients in Japan. Showa Univ. J. Med. Sci. 26, 27-38 (2014).

36. Gomez, A. C. \& Yamaguchi, N. Two regions of the ryanodine receptor calcium channel are involved in $\mathrm{Ca}^{2+}$-dependent inactivation. Biochemistry 53, 1373-1379 (2014).

37. Murayama, T. et al. Divergent activity profiles of type 1 ryanodine receptor channels carrying malignant hyperthermia and central core disease mutations in the amino-terminal region. PLoS One 10, e0130606 (2015).

38. Murayama, T. et al. Genotype-phenotype correlations of malignant hyperthermia and central core disease mutations in the central region of the RYR1 channel. Hum. Mutat. 37, 1231-1241 (2016).

39. Gomez, A. C., Holford, T. W. \& Yamaguchi, N. Malignant hyperthermia-associated mutations in the S2-S3 cytoplasmic loop of type 1 ryanodine receptor calcium channel impair calciumdependent inactivation. Am. J. Physiol. - Cell Ph. 311, C749-C757 (2016).

40. Yamazawa, T. et al. Insights into channel modulation mechanism of RYR1 mutants using $\mathrm{Ca}^{2+}$ imaging and molecular dynamics. J. Gen. Physiol. 152, e201812235 (2020).

41. Iyer, K. A. et al. Structural mechanism of two gain-of-function cardiac and skeletal RyR mutations at an equivalent site by cryo-EM. Sci. Adv. 6, eabb2964 (2020).

42. Oyama, K. et al. Single-cell temperature mapping with fluorescent thermometer nanosheets. J. Gen. Physiol. 152, e201912469 (2020).

43. Ishii, S. et al. Microscopic heat pulses activate cardiac thin filaments. J. Gen. Physiol. 151, 860869 (2019).

44. Tseeb, V., Suzuki, M., Oyama, K., Iwai, K. \& Ishiwata, S. Highly thermosensitive Ca ${ }^{2+}$ dynamics in a HeLa cell through IP 3 receptors. HFSP J. 3, 117-123 (2009).

45. Nakamura, N., Yamazawa, T., Okubo, Y. \& lino, M. Temporal switching and cell-to-cell variability in $\mathrm{Ca}^{2+}$ release activity in mammalian cells. Mol. Syst. Biol. 5, 247 (2009).

46. Bootman, M. D. et al. 2-Aminoethoxydiphenyl borate (2-APB) is a reliable blocker of storeoperated $\mathrm{Ca}^{2+}$ entry but an inconsistent inhibitor of $\mathrm{InSP}_{3}$-induced $\mathrm{Ca}^{2+}$ release. FASEB J. 16, 1145-1150 (2002).

47. Bilmen, J. G., Wootton, L. L., Godfrey, R. E., Smart, O. S. \& Michelangeli, F. Inhibition of SERCA $\mathrm{Ca}^{2+}$ pumps by 2-aminoethoxydiphenyl borate (2-APB): 2-APB reduces both $\mathrm{Ca}^{2+}$ binding and 
phosphoryl transfer from ATP, by interfering with the pathway leading to the $\mathrm{Ca}^{2+}$-binding sites. Eur. J. Biochem. 269, 3678-3687 (2002).

48. Hu, H. Z. et al. 2-Aminoethoxydiphenyl borate is a common activator of TRPV1, TRPV2, and TRPV3. J. Biol. Chem. 279, 35741-35748 (2004).

49. Maruyama, T., Kanaji, T., Nakade, S., Kanno, T. \& Mikoshiba, K. 2APB, 2-aminoethoxydiphenyl borate, a membrane-penetrable modulator of $\operatorname{Ins}(I, 4,5) \mathrm{P}_{3}$-induced $\mathrm{Ca}^{2+}$ release. J. Biochem. 122, 498-505 (1997).

50. Suzuki, J. et al. Imaging intraorganellar $\mathrm{Ca}^{2+}$ at subcellular resolution using CEPIA. Nat. Commun. 5, 4153 (2014).

51. de Meis, L., Arruda, A. P. \& Carvalho, D. P. Role of sarco/endoplasmic reticulum Ca ${ }^{2+}$-ATPase in thermogenesis. Biosci. Rep. 25, 181-190 (2005).

52. Tullis, A., Block, B. A. \& Sidell, B. D. Activities of key metabolic enzymes in the heater organs of scombroid fishes. J. Exp. Biol. 161, 383-403 (1991).

53. Durham, W. J. et al. RyR1 S-nitrosylation underlies environmental heat stroke and sudden death in Y522S RyR1 knockin mice. Cell 133, 53-65 (2008).

54. Lanner, J. T. et al. AICAR prevents heat-induced sudden death in RyR1 mutant mice independent of AMPK activation. Nat. Med. 18, 244-251 (2012).

55. Treves, S., Jungbluth, H., Muntoni, F. \& Zorzato, F. Congenital muscle disorders with cores: the ryanodine receptor calcium channel paradigm. Curr. Opin. Pharmacol. 8, 319-326 (2008).

56. Hwang, J. H., Zorzato, F., Clarke, N. F. \& Treves, S. Mapping domains and mutations on the skeletal muscle ryanodine receptor channel. Trends Mol. Med. 18, 644-657 (2012).

57. Tung, C.-C., Lobo, P. A., Kimlicka, L. \& Van Petegem, F. The amino-terminal disease hotspot of ryanodine receptors forms a cytoplasmic vestibule. Nature 468, 585-588 (2010).

58. Kimlicka, L., Lau, K., Tung, C.-C. \& Van Petegem, F. Disease mutations in the ryanodine receptor $\mathrm{N}$-terminal region couple to a mobile intersubunit interface. Nat. Commun. 4, 1506 (2013).

59. Lau, K. \& Van Petegem, F. Crystal structures of wild type and disease mutant forms of the ryanodine receptor SPRY2 domain. Nat. Commun. 5, 5397 (2014).

60. Zheng, W. \& Liu, Z. Investigating the inter-subunit/subdomain interactions and motions relevant to disease mutations in the $\mathrm{N}$-terminal domain of ryanodine receptors by molecular dynamics simulation. Proteins 85, 1633-1644 (2017).

61. Zheng, W. \& Wen, H. Investigating dual $\mathrm{Ca}^{2+}$ modulation of the ryanodine receptor 1 by molecular dynamics simulation. Proteins (2020). doi:10.1002/prot.25971

62. Poussel, M. et al. Exertional heat stroke and susceptibility to malignant hyperthermia in an athlete: evidence for a link? J. Athl. Train. 50, 1212-1214 (2015).

63. Roux-Buisson, N. et al. Identification of variants of the ryanodine receptor type 1 in patients with exertional heat stroke and positive response to the malignant hyperthermia in vitro contracture 
test. Br. J. Anaesth. 116, 566-568 (2016).

64. Laitano, O., Murray, K. O. \& Leon, L. R. Overlapping mechanisms of exertional heat stroke and malignant hyperthermia: evidence vs. conjecture. Sport. Med. 50, 1581-1592 (2020).

65. Murayama, T. et al. Role of amino-terminal half of the S4-S5 linker in type 1 ryanodine receptor (RyR1) channel gating. J. Biol. Chem. 286, 35571-35577 (2011).

66. Ohashi, Y. et al. A bicistronic lentiviral vector-based method for differential transsynaptic tracing of neural circuits. Mol. Cell. Neurosci. 46, 136-147 (2011).

67. Kobirumaki-Shimozawa, F. et al. Nano-imaging of the beating mouse heart in vivo: Importance of sarcomere dynamics, as opposed to sarcomere length per se, in the regulation of cardiac function. J. Gen. Physiol. 147, 53-62 (2016).

68. Kanda, Y. Investigation of the freely available easy-to-use software 'EZR' for medical statistics. Bone Marrow Transplant. 48, 452-458 (2013). 


\section{Figure legends}
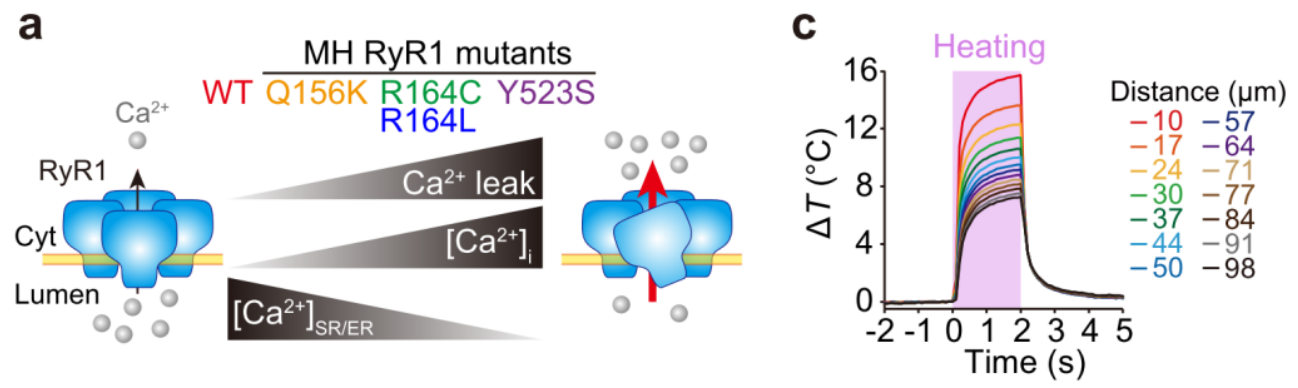

b

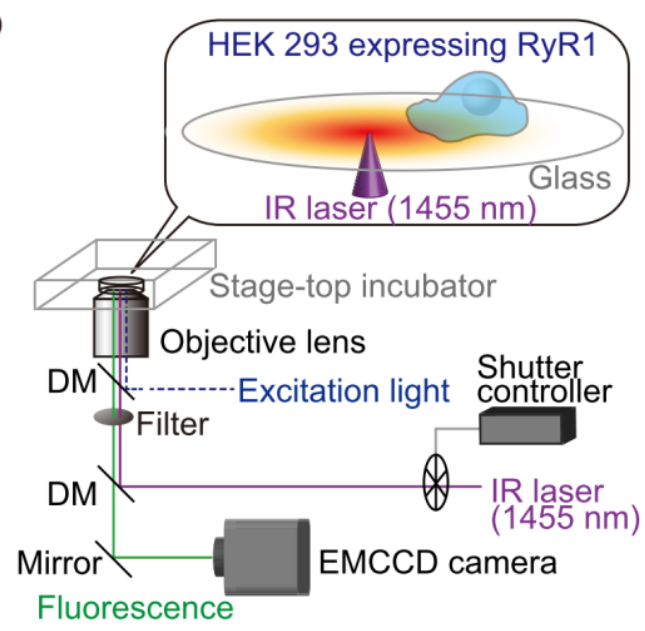

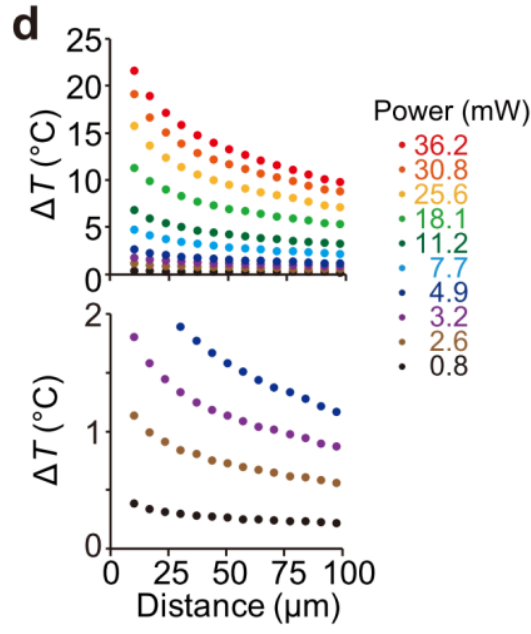

Figure 1. Experimental design to examine heat sensitivities of various malignant hyperthermia mutants of ryanodine receptor type 1.

(a) Properties of malignant hyperthermia $(\mathrm{MH})$ mutants of ryanodine receptor type 1 (RyR1) investigated in this study. $\mathrm{Ca}^{2+}$ leakage through mutant RyR1s (higher rank) is greater than that through wild-type (WT) receptors (the lowest rank). Cytoplasmic [ $\left.\mathrm{Ca}^{2+}\right]$ $\left(\left[\mathrm{Ca}^{2+}\right]_{\mathrm{i}}\right)$ of cells expressing RyR1 mutants is higher than that of cells expressing WT RyR1. The $\left[\mathrm{Ca}^{2+}\right]$ in sarco/endoplasmic reticulum $\left(\left[\mathrm{Ca}^{2+}\right]_{\mathrm{SR} / \mathrm{ER}}\right)$ is depleted because of the $\mathrm{Ca}^{2+}$ leakage. The rank order was based on the literature ${ }^{35,37}$. (b) Schematic illustration of the fluorescence microscopy set-up. A 1455-nm infrared (IR) laser beam was guided to the sample stage by a dichroic mirror (DM) and objective lens and focused on the medium. The temperature in the field of view was elevated locally because of the absorption of IR light by the aqueous medium. Sample temperature was controlled by a stage-top incubator. (c) Time courses of temperature changes $(\Delta T)$ at various distances from the heat source. The pink region indicates the period of heat pulse. Laser power, $25.6 \mathrm{~mW}$. (d) Temperature gradients formed by various laser powers. The bottom panel is the enlarged view of $\Delta T$ s between $0^{\circ} \mathrm{C}$ and $2^{\circ} \mathrm{C}$. 

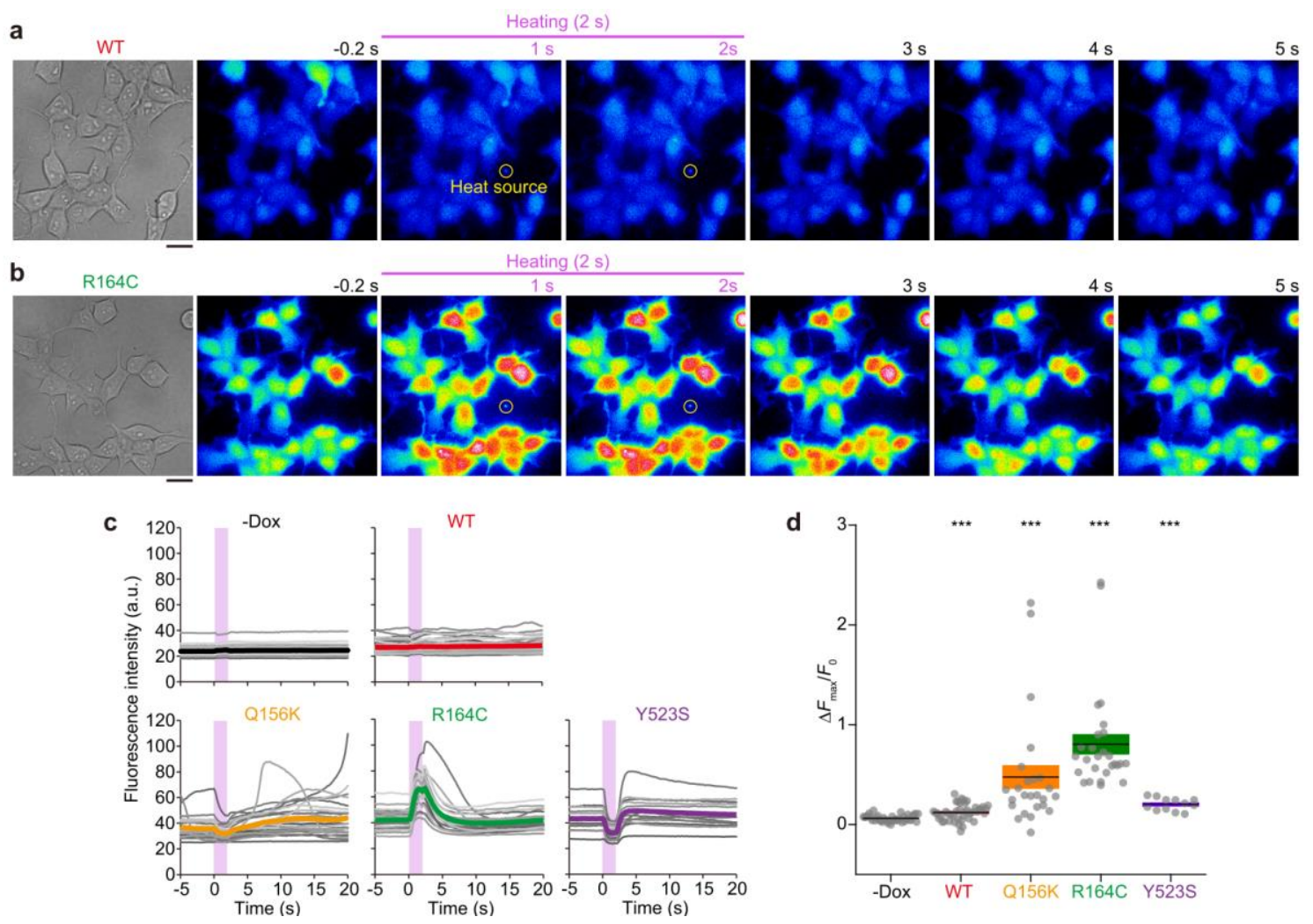

Figure 2. Intracellular $\mathrm{Ca}^{2+}$ responses to heat pulses in HEK 293 cells expressing ryanodine receptor type 1 mutants.

(a and b) Bright-field and fluorescence images of fluo-4-loaded HEK 293 cells expressing WT RyR1 (a) and R164C (b). Background increase during heating was caused by IR laser beam scattering (apparent in Supplementary Movie 1). Yellow circles indicate the position of the heat source. Scale bars, $20 \mu \mathrm{m}$. (c) Changes in the fluorescence intensity of fluo-4. Each gray curve represents an individual cell. The thick colored curves indicate the average intensities. Pink regions indicate the periods of the heat pulses. (d) Maximum changes in relative fluorescence intensity of fluo-4 $\left(\Delta F_{\max } / F_{0}\right)$ during the $20 \mathrm{~s}$ after heating initiation. Horizontal bars and error bars indicate the means \pm SEM. Statistical significance was determined by comparison with -Dox cells $(n=40)$ using the Steel test $\left({ }^{* * *} p<0.001\right)$. WT, $n=43$ and $p=3.5 \times 10^{-4} ; \mathrm{Q} 156 \mathrm{~K}, \mathrm{n}=25$ and $p=5.3 \times 10^{-8} ; \mathrm{R} 164 \mathrm{C}$, $\mathrm{n}=27$ and $p=1.5 \times 10^{-11} ; \mathrm{Y} 523 \mathrm{~S}, \mathrm{n}=12$ and $p=1.9 \times 10^{-6}$. Laser power, $25.6 \mathrm{~mW} ; \Delta T=10 \pm 2^{\circ} \mathrm{C}$; $T_{0}=24^{\circ} \mathrm{C}$. 

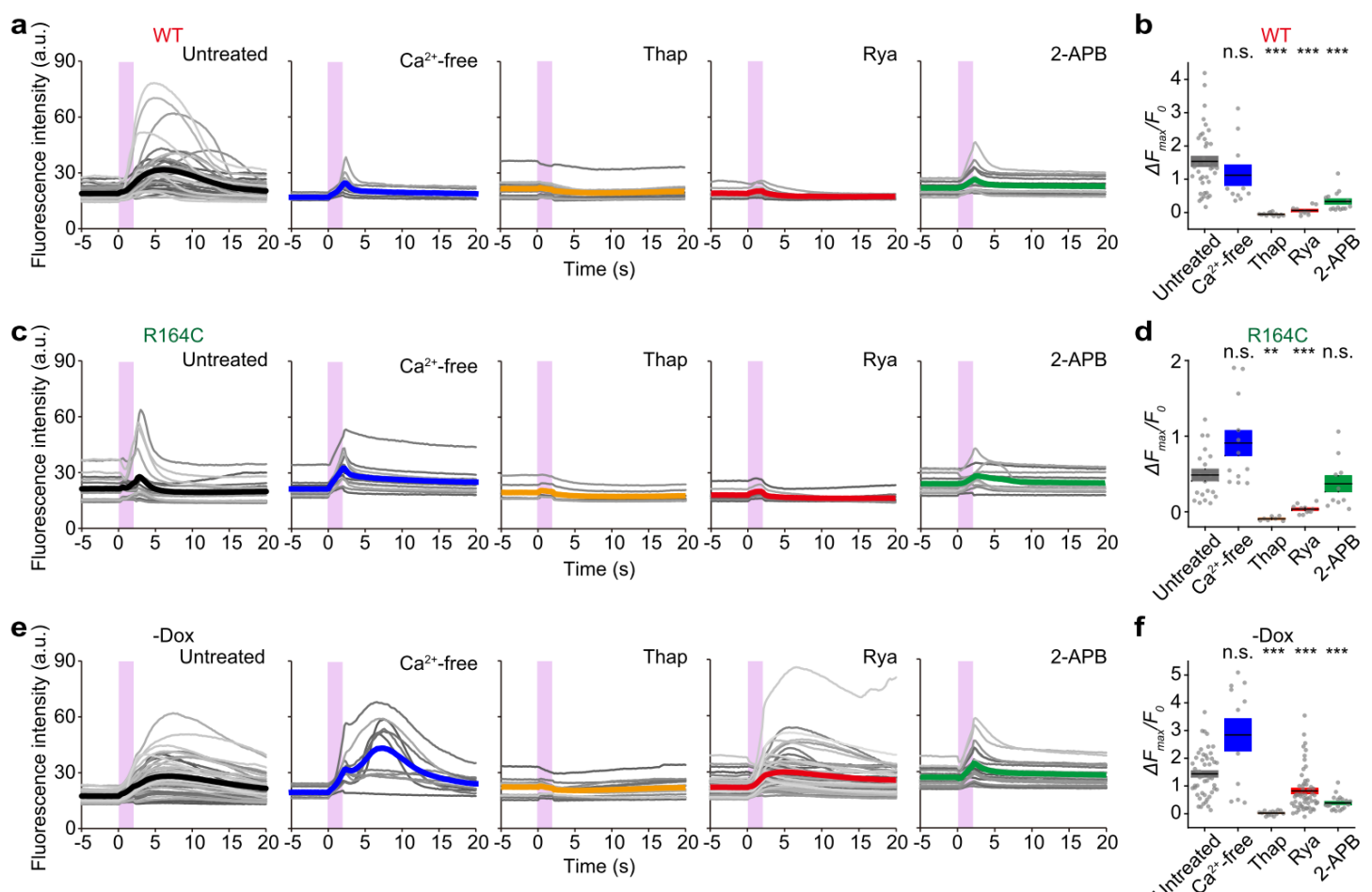

Figure 3. Contribution of ryanodine receptors and inositol trisphosphate receptors to heat-induced $\mathrm{Ca}^{2+}$ bursts.

$\left(\mathrm{a}, \mathrm{c}\right.$, and e) Time courses of the fluorescence intensity of fluo-4 in untreated cells, $\mathrm{Ca}^{2+}-$ free solution ( $\mathrm{Ca}^{2+}$-free), and in the presence of $2 \mu \mathrm{M}$ thapsigargin (Thap), $100 \mu \mathrm{M}$ ryanodine (Rya), or $100 \mu \mathrm{M}$ 2-aminoethyl diphenylborinate (2-APB). Gray curves represent individual cells. The thick colored curves represent averages. Pink regions indicate the periods of the heat pulses. (a) WT, (c) R164C, (e) -Dox. (b, d, and f) Maximum changes in relative fluorescence intensity, $\Delta F_{\max } / F_{0}$. Horizontal bars and error bars indicate the means \pm SEM. (b) WT, (d) R164C, (f) -Dox. Statistical significance was examined by comparison with the untreated cells using the Steel test $(* * p<0.01$; ${ }^{* * *} p<0.001$; n.s., not significant). Data for WT, $p=0.51$ (Ca ${ }^{2+}$-free), $3.8 \times 10^{-7}$ (Thap), 7.2 $\times 10^{-6}$ (Rya), and $1.4 \times 10^{-5}$ (2-APB). Data for R164C, $p=0.11$ (Ca ${ }^{2+}$-free), 0.0013 (Thap), $9.7 \times 10^{-5}$ (Rya), and 0.91 (2-APB). Data for -Dox, $p=0.18$ (Ca ${ }^{2+}$-free), $2.4 \times 10^{-8}$ (Thap), 1.5 $\times 10^{-5}$ (Rya), and $2.3 \times 10^{-6}(2-\mathrm{APB})$. Laser power, $25.6 \mathrm{~mW} ; \Delta T=10 \pm 1^{\circ} \mathrm{C} ; T_{0}=36^{\circ} \mathrm{C}$. 

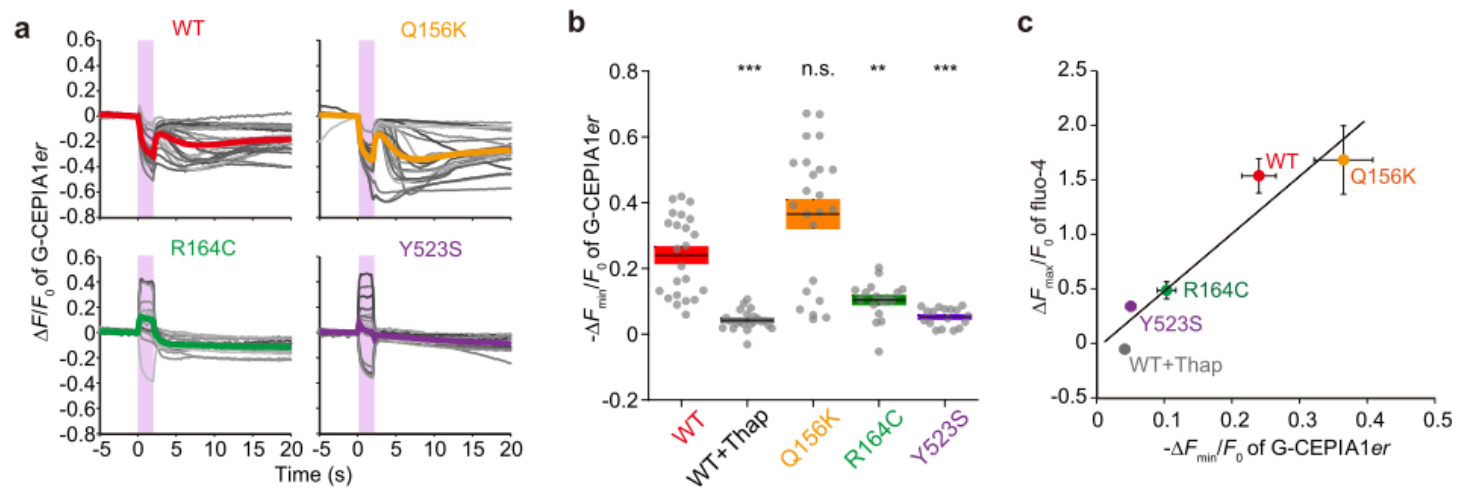

Figure 4. Heat-induced $\mathrm{Ca}^{2+}$ release from the endoplasmic reticulum.

(a) Relative change in the fluorescence intensity, $\Delta F / F_{0}$, of G-CEPIA1er in cells expressing WT, Q156K, R164C, or Y523S. Data in Supplementary Fig. 3a were analyzed and plotted. $n=23,23,18$, and 16 cells for WT, Q156K, R164C, and Y523S, respectively. Pink regions indicate the periods of heat pulses. (b) Minimum relative change in G-CEPIA1er fluorescence intensity $-\Delta F_{\min } / F_{0}$ after heating. Statistical significance was determined by comparison with WT using the Steel test $\left({ }^{*} p<0.05 ;{ }^{* *} p<0.01 ; * * * p<0.001\right) . p=1.0 \times 10^{-7}$ (WT + Thap), 0.086 (Q156K), 0.0035 (R164C), and $2.0 \times 10^{-6}$ (Y523S). Horizontal bars and error bars indicate the means \pm SEM. (c) Relationship between the change in $\left[\mathrm{Ca}^{2+}\right]_{\mathrm{er}}$ $\left(-\Delta F_{\min } / F_{0}\right.$ of G-CEPIA1er) and $\left[\mathrm{Ca}^{2+}\right]_{\mathrm{i}}\left(\Delta F_{\text {max }} / F_{0}\right.$ of fluo-4; Supplementary Fig. 2$)$. The correlation coefficient $R=0.96(p=0.011)$. Laser power, $25.6 \mathrm{~mW} ; \Delta T=10 \pm 1^{\circ} \mathrm{C} ; T_{0}=36^{\circ} \mathrm{C}$. 

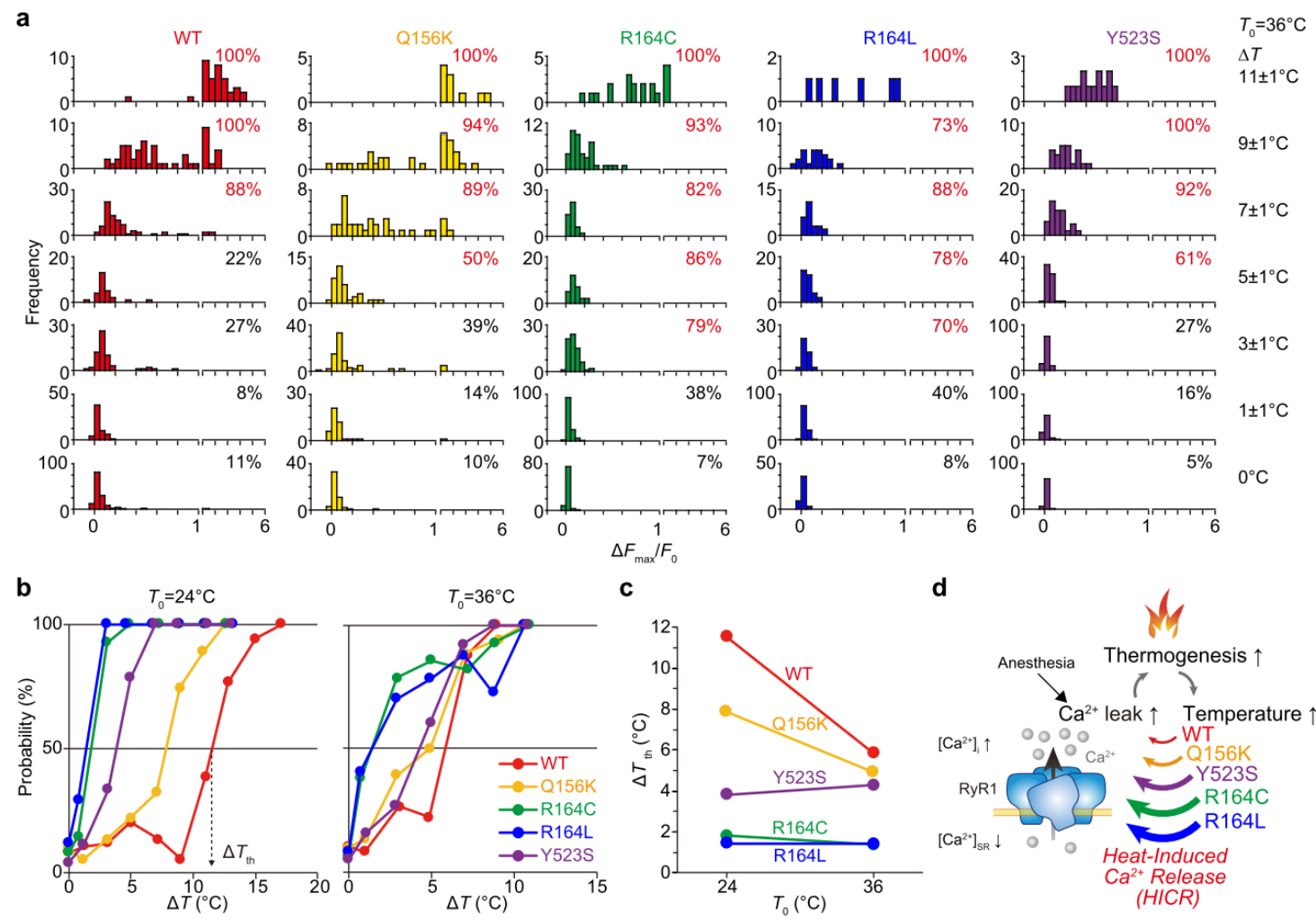

\section{Figure 5. Rank order of ryanodine receptor type 1 mutants' heat sensitivity.}

(a) Histograms showing $\left[\mathrm{Ca}^{2+}\right]_{i}$ increases $\left(\Delta F_{\max } / F_{0}\right.$ s of fluo-4) in response to heat pulses of various amplitudes $(\Delta T)$. The numbers on the top right of each panel indicate the response probability that the cells showed significant $\left[\mathrm{Ca}^{2+}\right]_{\mathrm{i}}$ increase $\left(\Delta F_{\min } / F_{0}>\Delta F_{\text {th }}\right)$. Data in Supplementary Fig. 4 were analyzed and plotted. $T_{0}=36^{\circ} \mathrm{C}$. (b) Relationship between $\Delta T$ and the response probability. The $\Delta T_{\text {th }}$ is defined as the $\Delta T$ at which the response probability $=50 \%$. (c) Relationship between $T_{0}$ and $\Delta T_{\text {th }}$. Rank order in $\Delta T_{\text {th }}$ at $T_{0}=36^{\circ} \mathrm{C}$ was R164C $\left(1.4^{\circ} \mathrm{C}\right)=\mathrm{R} 164 \mathrm{~L}\left(1.4^{\circ} \mathrm{C}\right)<\mathrm{Y} 523 \mathrm{~S}\left(4.3^{\circ} \mathrm{C}\right)<\mathrm{Q} 156 \mathrm{~K}\left(4.9^{\circ} \mathrm{C}\right)<\mathrm{WT}\left(5.8^{\circ} \mathrm{C}\right)$. The rank order at $T_{0}=24^{\circ} \mathrm{C}$ was R164L $\left(1.4^{\circ} \mathrm{C}\right) \approx \mathrm{R} 164 \mathrm{C}\left(1.8^{\circ} \mathrm{C}\right)<\mathrm{Y} 523 \mathrm{~S}\left(3.8^{\circ} \mathrm{C}\right)<\mathrm{Q} 156 \mathrm{~K}$ $\left(7.9^{\circ} \mathrm{C}\right)<$ WT $\left(11.5^{\circ} \mathrm{C}\right)$. (d) Schematic illustration of proposed positive-feedback loop closed by heat-induced $\mathrm{Ca}^{2+}$-release (HICR) explaining $\mathrm{MH}$ initiation and its aggravation. Anesthesia-triggered $\mathrm{Ca}^{2+}$ leak through $\mathrm{MH}$ RyR1 mutants induces hyperthermia. The temperature rise destabilizes RyR1 and causes HICR. 